\title{
O AMBIENTE AÉREO E A RELAÇÃO COM A ASSISTÊNCIA DE ENFERMAGEM EM VOO: A IMPORTÂNCIA DA CAPACITAÇÃO
}

Débora Fernanda HABERLAND ${ }^{(1)}$; Fábio José De Almeida GUILHERME ${ }^{2)}$; Letícia Lima BORGES ${ }^{(3)}$; Adriana de Oliveira GARRIDO ${ }^{(4)}$

\section{RESUMO}

Introdução: A equipe de transporte aeromédico precisa de sólidos conhecimentos em fisiologia aeroespacial para prestar cuidados em voo. Neste sentido, esse estudo tem como Objeto: o entendimento da importância da capacitação e dos conhecimentos essenciais de fisiologia aeroespacial que são necessários para uma assistência de enfermagem de qualidade. O Objetivo deste trabalho é refletir sobre a influência do ambiente aéreo e sua relação com a assistência de enfermagem em voo, destacando a importância da capacitação. Materiais e Método: Estudo de revisão integrativa, na base de dados do Scielo e BVS. Resultados e Discursão: Após leitura criteriosa dos artigos selecionados, foram evidenciadas três temáticas principais. $\mathrm{O}$ ambiente aéreo, o transporte aeromédico e a capacitação do enfermeiro para atuação em transporte aeromédico. Conclusões: A capacitação do enfermeiro em enfermagem aeroespacial é essencial para que ele desenvolva habilidades e possa realizar um planejamento do transporte de forma segura, fatores estes que contribuem com qualidade e segurança do cuidado prestado e na ampliação do espaço de atuação. Há uma assistência de qualidade. No entanto, embora haja consenso sobre essa importância, verificou-se escassez de estudos científicos nas bases de dados sobre essa regulamentação.

\section{PALAVRAS-CHAVE}

Medicina aeroespacial; Enfermagem; Transporte Aéreo; Capacitação.

\footnotetext{
(1) Enfermeira Doutora, Oficial da Força Aérea Brasileira - FAB, 1ำ Tenente atualmente servindo no Instituto de Medicina Aeroespacial - IMAE no Rio de Janeiro, Brasil. deborahaber@hotmail.com

(2) Enfermeiro Mestre, Oficial da Força Aérea Brasileira - FAB, 2ำ Tenente atualmente servindo no Instituto de Medicina Aeroespacial - IMAE no Rio de Janeiro, Brasil. fabioguilhermefjag@fab.mil.br

${ }^{(3)}$ Enfermeira Mestranda do PPGENF - UNIRIO e Oficial da Força Aérea Brasileira - FAB, 1o Tenente atualmente servindo no Instituto de Medicina Aeroespacial - IMAE no Rio de Janeiro, Brasil. lima.leticia.borges@gmail.com

(4) Enfermeira especialista e Suboficial da Força Aérea Brasileira - FAB, atualmente servindo no Instituto de Medicina Aeroespacial - IMAE no Rio de Janeiro, Brasil. adripinheiro08@gmail.com
} 


\section{INTRODUÇÃO}

$\mathrm{Na}$ atividade aérea, devido à peculiaridade do ambiente aéreo, diversos fatores estão relacionados com estresse de voo, desde mudanças como a variação de altitude, acelerações, como fatores dos vetores, seja de asas rotativas ou fixas. Podemos citar: ruídos, vibração, baixa umidade do ar, baixa pressão parcial de oxigênio (risco de hipóxia), fadiga, variações de temperatura, baixa luminosidade, aerocinetose, alteração do ciclo circadiano, aerodilatação, barotraumas e incidência de radiação.

É de grande importância que os trabalhadores desta área tenham conhecimento sobre o assunto a fim de realizar um planejamento do transporte de forma adequada, pois as alterações devido o ambiente aéreo podem interferir diretamente na evolução do transporte. Segundo Gomes (2018), É fundamental que estes profissionais estejam treinados e saibam avaliar as situações que possam ocorrer em altitude, como a medicina aeroespacial é uma área específica, requer atenção e cuidado para avaliar o paciente, além de uma boa comunicação entre a equipe para avaliação e conduta.

Ao refletir sobre a atuação do enfermeiro na atuação aeroespacial, foco deste estudo, é importante desenvolver diversas habilidades para saber lidar com todas as situações possíveis no ambiente aeroespacial. O objetivo deste trabalho é refletir sobre a influência do ambiente aéreo e a relação com a assistência de enfermagem em voo, destacando a importância da capacitação

\section{METODOLOGIA}

Estudo de revisão integrativa, elaborado a partir de uma revisão da literatura nas bases de dados do Scientific Electronic Library (Scielo) e na Biblioteca Virtual de Saúde (BVE), no período entre 2008 a 2021. Foram inclusos os artigos que tivessem em suas palavras chaves as palavras: enfermagem aeroespacial, transporte aeromédico e fisiologia aeroespacial. Foram excluídos os que não diziam respeito ao propósito deste estudo.

\section{RESULTADOS E DISCUSSÕES}

Após leitura criteriosa dos artigos selecionados, foram evidenciadas três temáticas principais. $\mathrm{O}$ ambiente aéreo, o transporte aeromédico e a capacitação do enfermeiro para atuação em transporte aeromédico. 


\section{O AMBIENTE AÉREO}

Segundo Sousa (2019), o estudo da Fisiologia do Voo auxilia na compreensão de determinados fenômenos físicos que permitem prestar uma assistência em saúde de alta qualidade ao paciente aerotransportado.

É importante destacar que o transporte aeromédico não é apenas uso de aeronave para transporte, requer capacitação e conhecimentos específicos além do Atendimento Pré Hospitalar (APH), mas relacionados à fisiologia de altitude estando apto a atender, remover e agir diante de situações críticas, e oferecer melhor atendimento ao paciente.

Segundo a Portaria no 2.048/2002, para atuar no ambiente aeroespacial o profissional de enfermagem deve ter noções básicas de aeronáutica, terminologia aeronáutica, procedimentos normais de emergência de voo, evacuação aérea de emergência, segurança no interior e entorno da aeronave, embarque e desembarque de pacientes e noções básicas de fisiologia de voo (BRASIL, 2002).

\section{O TRANSPORTE AEROMÉDICO}

De acordo com a Portaria no 2.048/2002 do Ministério da Saúde, define ambulância como um veículo que se destina exclusivamente ao transporte de enfermos. $O$ transporte Aeromédico utilizado no atendimento pré-hospitalar (APH) refere-se ao "Tipo E", que é definido como aeronave de asa fixa ou rotativa utilizada para transporte inter-hospitalar de pacientes e aeronave de asa rotativa para ações de resgate, dotada de equipamentos médicos homologados pelo Departamento de Aviação Civil - DAC. É considerada sempre como uma viatura de suporte avançado. Tripulação: piloto, um médico e um enfermeiro; um resgatista pode ser associado, se necessário (LIBARDI, 2019).

O transporte aeromédico do paciente enfermo somente terá sucesso se for realizada uma criteriosa avaliação da situação, incluindo o acesso e a estabilização do paciente antes do voo, se houver uma equipe adequadamente preparada, com todo o material necessário para o correto manuseio durante o voo, e uma tripulação de voo com todas as qualificações exigidas para realizar um transporte seguro.

Segundo Silva (2019), as diferentes habilidades de cada tripulante são utilizadas de forma a complementar para alcançar o resultado almejado no ambiente aeroespacial. Portanto, é necessário que este profissional seja 
competente para tal, ou seja, tenha conhecimentos, habilidades e atitudes que, quando mobilizados ajudam-no a desempenhar bem as suas funções.

\section{O ENFERMEIRO AEROESPACIAL}

Destaca-se a pouca abordagem de regulamentação no que se refere às atribuições do enfermeiro de bordo, enfatizando a complexidade e a especificidade na remoção dos pacientes do local do acidente até o ambiente hospitalar (PASSOS, 2009).

Segundo Brasil (2002), as atribuições do enfermeiro aeroespacial devem estar de acordo com a Lei do Exercício Profissional e do Código de Ética de Enfermagem e o COFEN (2017), participar de treinamento e aprimoramento pessoal em emergência, fazer o controle da qualidade do serviço, participar da padronização dos materiais e equipamentos presentes na aeronave. Além disso, as ações podem ser dividas em pré-voo, durante o voo e no pós-voo.

\section{CONCLUSÃO}

Identificou-se que o trabalho na área de enfermagem aeroespacial apresenta especificidades próprias e para isso necessita de um campo de conhecimentos também próprios. Nesse sentido, conhecimentos novos não apenas sobre técnicas, apoio a tripulação, planos de cuidados, comunicação, trabalho em equipe, reações à altitude e relativas à gestão de enfermagem que se enquadrem a essa modalidade organizacional são de grande importância e podem contribuir na formação de habilidades do enfermeiro aeroespacial.

No entanto, embora haja consenso sobre essa importância, verificou-se que a legislação referente à atuação do enfermeiro como especialista em enfermagem aeroespacial é recente. Acredita-se que estudos voltados para a atuação do enfermeiro de bordo e da influência da fisiologia aeroespacial, são importantes para evidenciar mais uma área de atuação da profissão e na melhoria da assistência oferecida. 


\section{REFERÊNCIAS}

BRASIL. Ministério da Saúde. Portaria no 2.048/2002. Brasília 2002. Disponível em http://bvsms.saude.gov.br/bvs/saudelegis/gm/2002/prt2048_05_11_2002.html

COFEN, Conselho Federal de Enfermagem. Cofen normatiza atuação do enfermeiro aeroespacial. Mato Grosso, 2017. Disponível em: < http://mt.corens.portalcofen.gov.br/cofen-normatiza-atuacao-do-enfermeiroaeroespacial_3955. html>. Acesso em: 10 fev 2019.

GOMES ED. Necessidade de atualização do treinamento fisiológico na Força Aérea Brasileira. Escola de Aperfeiçoamento de Oficiais da Aeronáutica EAOR. Rio de Janeiro RJ. 2018

LIBARDI MBO. Transporte do Paciente Crítico e Resgate Aeromédico. PósGraduação em Enfermagem Aeroespacial. Universidade Unyleya. Brasília, 2019.

MELLO, M. P. Avaliação de estresse e saúde profissional. Trabalho de Conclusão de Curso. Psicologia. Universidade Anhanguera Educacional. Campus III. Campinas. 2014.

SOUSA, V.V. Fisiologia e Fisiopatologia de Voo. Pós Graduação em Enfermagem Aeroespacial. Faculdade Unyleya. Brasília. 2019

PASSOS, et al. Transporte aéreo de pacientes: análise do conhecimento científico. Rev Bras Enferm, Brasilia 2011 nov-dez; 64(6): 1127-31.disponivel em http://www.scielo.br/scielo.php?script=sci_arttext\&pid=S0034-71672011000600021. Acesso em 05 Março 2019. 